\title{
Dysphagia after stroke: an overview
}

\author{
Marlís González-Fernández • Lauren Ottenstein • \\ Levan Atanelov • Asare B. Christian
}

Published online: 3 May 2013

(c) Springer Science+Business Media New York 2013

\begin{abstract}
Dysphagia affects the vast majority of acute stroke patients. Although it improves within 2 weeks for most, some face longstanding swallowing problems that place them at risk for pneumonia, malnutrition, dehydration, and significantly affect quality of life. This paper discusses the scope, the disease burden, and the tools available for screening and formal evaluation of dysphagia. The most common and recently developed treatment interventions that might be useful in the treatment of this population are discussed.
\end{abstract}

Keywords Dysphagia $\cdot$ Stroke $\cdot$ Swallowing $\cdot$ Deglutition

\section{Introduction}

For the vast majority of the 6.2 million stroke survivors [1] in the US one of the first hurdles on the path to recovery is swallowing dysfunction. Dysphagia not only increases morbidity and mortality after stroke but also significantly affects quality of life when it is not possible to share meals with family and friends. Prompt evaluation and treatment of swallowing disorders can mitigate the development of secondary complications and foster prompt reintegration into society.

M. González-Fernández $(\varangle) \cdot$ L. Atanelov · A. B. Christian Outpatient PM\&R Clinics, Johns Hopkins Hospital, 600 North Wolfe St. Phipps 174, Baltimore, MD 21287, USA

e-mail: mgonzal5@jhmi.edu

L. Ottenstein

Department of Physical Medicine and Rehabilitation, Johns Hopkins University School of Medicine, 600 North Wolfe St. Phipps 174, Baltimore, MD 21287, USA

\section{Epidemiology}

Dysphagia affects more than $50 \%$ of stroke survivors [2]. Fortunately, the majority of these patients recover swallowing function within 7 days, and only 11-13\% remain dysphagic after 6 months [3, 4]. One study reported that $80 \%$ of patients with prolonged dysphagia required alternative means of enteral feeding [5].

The most feared complication of dysphagia after stroke is aspiration pneumonia. Dysphagia identified during bedside clinical examination was associated with an increase of $17 \%$ in the incidence of pulmonary infection compared to those that were not dysphagic (33\% vs. $16 \%$ respectively) [6]. In the same study mortality was more than $30 \%$ in stroke survivors with dysphagia. Dehydration and malnutrition also are common in dysphagic patients especially those who receive thickened liquids or modified diets. One study reported that $49 \%$ of stroke survivors admitted to a rehabilitation unit were malnourished, and that malnutrition was associated with dysphagia [7]. Gordon et al. [8] reported that approximately $58 \%$ of acute stroke survivors with dysphagia had signs of dehydration (urea concentration of $10 \mathrm{mmol} / \mathrm{l}$ or higher) compared to $32 \%$ of those that were not dysphagic.

Dysphagia can adversely impact quality of life. Only $45 \%$ of patients with dysphagia find eating enjoyable, and $41 \%$ of patients with dysphagia experience anxiety or panic during mealtimes [9]. More than $1 / 3$ of patients avoid eating with others because of dysphagia [9].

\section{Swallowing physiology}

Swallowing requires food passage from the mouth through the esophagus and into the stomach without compromising 
the adjacent structures: nasal passages, larynx and the lower respiratory tract. The process starts after food ingestion and can be divided into four stages defined by the location of the bolus: [10]

(1) Oral preparatory stage: prepare bolus for propulsion into pharynx.

(2) Oral propulsive stage: tongue pushes bolus through the fauces into the pharynx.

(3) Pharyngeal phase: pharyngeal structures move bolus through the upper esophageal sphincter.

(4) Esophageal phase: esophageal peristalsis and gravity move the bolus through the lower esophageal sphincter into the stomach.

More detailed perspectives on swallowing physiology can be found in reviews by Cecconi and Di Piero, Miller, and Matsuo and Palmer [11-13].

\section{Oral stage}

Once a liquid bolus is ingested, the oral cavity is sealed off between the dorsal tongue and the soft palate to prevent leakage into the pharynx until ready for swallowing. During the propulsive stage the tip of the tongue contacts the hard palate behind the upper anterior teeth and the tongue surface moves upward. The tongue-palate contact area expands posteriorly and squeezes the liquid bolus into the oropharynx.

In contrast, when eating solids, the tongue shifts backwards and rotates its surface to one side pulling the food back to the molar region and placing it on the occlusal surfaces for mastication (also known as stage 1 transport). During mastication oral structures work to reduce bolus size and soften it in preparation for the pharyngeal stage [14-16]. Between mastication cycles particles that have reached the appropriate size and consistency are moved to the dorsal tongue surface and are transferred to the oropharynx (Stage 2 transport) [17]. These particles may accumulate for several seconds until a critical mass is reached and the pharyngeal stage of the swallow takes place.

Pharyngeal phase

Pharyngeal transport requires multiple coordinated and almost simultaneous events: [18-20].

(1) The soft palate elevates and seals the nasopharynx.

(2) Pharyngeal tongue surface pulls back while the pharyngeal wall contracts squeezing the bolus downward. The pharynx contracts sequentially from top to bottom [21], and shortens vertically to reduce its volume [22].
(3) The hyoid and larynx move superiorly and anteriorly while the epiglottis folds backwards sealing the laryngeal vestibule. These motion helps protect the airway [23].

(4) The vocal folds close the glottis [24-26] and interrupt breathing for $0.4-1.0 \mathrm{~s}$ to prevent aspiration [27, 28].

(5) The upper esophageal sphincter (UES) opens by a combination of cricopharyngeus relaxation (UES is held closed by its active contraction), suprahyoid muscle contraction, and the force of gravity generated by the down-moving bolus [23, 29].

Esophageal phase

Once the bolus passes through the UES, peristalsis and gravity move it down to the lower esophageal sphincter through which food reaches the stomach.

\section{Neural control of swallowing}

Normal control of swallowing requires appropriate function of the brain stem, the basal ganglia, the thalamus, the limbic system, the cerebellum, and the motor and sensory cortices (Table 1). These systems control afferent and efferent, anticipatory and preparatory, voluntary and automatic processes. Over 30 muscles are involved in swallowing and are coordinated by a complex neural network that is not completely understood.

The central pattern generator (CPG) for swallowing is located in the area of the nucleus tractus solitarius (NTS), the reticular formation, and nucleus ambiguus (NA) in the rostral and ventrolateral medulla [30-32]. Its interneuronal network controls timing of the deglutition phases and integrates sensory and supramedullary afferent with efferent processes [30].

Sensory input from mechanoreceptors, chemoreceptors and thermoreceptors in the oral cavity, pharynx and larynx to the CPG has been shown to affect swallowing initiation, facilitation and airway protection [31-34]. The oral cavity sensory neurons synapse in the trigeminal sensory nuclei, while pharyngeal and laryngeal sensory neurons travel in branches of CN IX, X and XI to synapse in the NTS [35].

The ventral CPG premotor neurons connect with $\mathrm{CN} V$, VII and XII and CN IX and X in the NA [31]. Timing of motor outputs varies with bolus characteristics [36]. Functionally, these peripheral connections coordinate different phases of deglutition. For instance, peripheral feedback inhibits the esophageal swallow during the pharyngeal swallow. It is likely that the trigeminal nucleus and reticular formation control the oral phase. The NTS regulates the sensation and pattern-generation, with the NA 
Table 1 Neural regions associated with swallowing function

\begin{tabular}{|c|c|c|}
\hline Region & Hypothesized role & References \\
\hline $\begin{array}{l}\text { Primary somatosensory, motor and Motor } \\
\text { Supplementary cortices (BA 1,2, 3, 4, and } \\
\text { 6) }\end{array}$ & $\begin{array}{l}\text { Cortical processing of swallowing, including } \\
\text { motor regulation and execution and motor } \\
\text { control }\end{array}$ & $\begin{array}{l}\text { Hamdy et al. [97], [98], Mosier and } \\
\text { Bereznaya [99], Martin et al. [100] }\end{array}$ \\
\hline Anterior cingulate (BA 24 and 32) & $\begin{array}{l}\text { Higher order motor processing: swallowing } \\
\text { movement planning and execution } \\
\text { Cognitive perceptual processes such as attention } \\
\text { and response selection }\end{array}$ & $\begin{array}{l}\text { Hamdy et al. [97], [98], Martin et al. [100], } \\
\text { Martin et al. [101] }\end{array}$ \\
\hline $\begin{array}{l}\text { Orbitofrontal cortex (BA 10, 11, 12, 44, 45, } \\
\text { and 47) }\end{array}$ & Unclear & Mosier et al. [102] \\
\hline Parieto-occipital cortex (BA 7, 17, 18, 40) & $\begin{array}{l}\text { Sensory processing of swallowing } \\
\text { Task-cue processing, not swallowing per se } \\
\text { Movement planning and execution }\end{array}$ & $\begin{array}{l}\text { Hamdy et al. [97], Kern et al. [103], } \\
\text { Toogood et al. [104], Mosier and } \\
\text { Bereznaya [99] }\end{array}$ \\
\hline Temporopolar cortex (BA 22 and 38) & Unclear & Mosier et al. [102] \\
\hline Insular cortex & $\begin{array}{l}\text { Processing of gustatory input } \\
\text { Intraoral sensory modulation }\end{array}$ & $\begin{array}{l}\text { Daniels et al. [105], Daniels and Foundas } \\
\text { [106], Mosier et al. [107], [102] }\end{array}$ \\
\hline Internal capsule & $\begin{array}{l}\text { Functional connection of the cortical and brain } \\
\text { stem nuclei via the corticobulbar tracts }\end{array}$ & $\begin{array}{l}\text { Mosier et al. [107], [102], Gonzalez- } \\
\text { Fernandez et al. [60] }\end{array}$ \\
\hline Thalamus & $\begin{array}{l}\text { Sensory and motor input processing via } \\
\text { thalamocortical and thalamostriatal pathways }\end{array}$ & Daniels et al. [105], Mosier et al. [102] \\
\hline Basal ganglia (caudate and/or putamen) & Gating of Sensory Output & $\begin{array}{l}\text { Mosier and Bereznaya [99], Daniels et al. } \\
\text { [105], Suzuki et al. [108] }\end{array}$ \\
\hline Cerebral peduncle & Descending pathways from the cortex & Miller [109] \\
\hline Brain stem & Central pattern generator, swallowing regulation & Jean [110], [111], [112] \\
\hline Cerebellum & $\begin{array}{l}\text { Regulation of adaptive coordination, sequencing, } \\
\text { timing, learning and memory of motion }\end{array}$ & $\begin{array}{l}\text { Zald and Pardo [113], Mosier and Bereznaya } \\
\text { [99], Suzuki et al. [108] }\end{array}$ \\
\hline
\end{tabular}

and dorsal motor nucleus controlling motor efferents for pharyngeal and esophageal phases [37]. The ventromedial nucleus of the NTS may be responsible for coupling the pharyngeal and esophageal phases [37]. Since these areas are crucial for pattern generation a lateral medullary stroke (Wallenberg's syndrome) can result in dysphagia that is usually severe and results in aspiration [34, 38]. This lesion affects the CPG and the CNs involved in swallowing; paralyzes or weakens the ipsilateral pharynx, larynx and the soft palate; and initiates and coordinates the pharyngeal stage of deglutition. Notably, electrophysiological studies demonstrate that the acute disconnection of contralateral swallowing centers also takes place [34].

Several supratentorial structures are associated with swallowing. In stroke, the size of the unaffected swallowing cortical area predicts dysphagia symptoms [39]. Voluntary initiation of deglutition requires cortical motor inputs [33, 40•, 41]. The motor and pre-motor cortices control deglutition bilaterally but asymmetrically [42] with no clear left-right laterality [43]. Recovery from supratentorial stroke induced dysphagia has been associated with compensatory cortical reorganization [44].

Suprabulbar palsy associated with dysphagia, dysarthria, dysphonia, loss of voluntary tongue and face movement and emotional lability, may be caused by bilateral lacunar infarcts or amyotrophic lateral sclerosis. Dysphagia in these patients has been correlated with lesions in the basal ganglia resulting in poor swallow triggering and upper esophageal sphincter control [45].

Lesions in the left periventricular white matter may be more disruptive to swallowing behavior than those on the right [46]. Oral transfer can be significantly impaired in patients with purely subcortical strokes [46]. Using positron emission topography (PET) researchers have identified asymmetric swallow-associated loci in the right orbitofrontal cortex, left mesial premotor cortex and cingulate, right caudolateral sensorimotor cortex, right anterior insula, bilateral medial cerebellum and bilateral temporopolar cortices with the strongest signals in the sensorimotor cortices, insula and cerebellum [47].

Leopold and Daniels [40॰] have documented the roles of brain locations and swallowing stages.

\section{Dysphagia screening}

Dysphagia screening serves to determine the possibility of aspiration (overt or silent) before complications such as pneumonia, dehydration, malnutrition, or airway obstruction develop. Multiple clinical tools have varying 
Table 2 Dysphagia screening tests

\begin{tabular}{|c|c|c|c|c|c|c|}
\hline Test & $\begin{array}{l}\text { Gold standard for } \\
\text { validation }\end{array}$ & $\begin{array}{l}\text { Includes clinical } \\
\text { evaluation }\end{array}$ & $\begin{array}{l}\text { Includes } \\
\text { sensory testing }\end{array}$ & $\begin{array}{l}\text { Water trial } \\
\text { protocol }\end{array}$ & Sensitivity & Specificity \\
\hline Burke dysphagia screening test & VFSS & Yes & No & $\begin{array}{l}\text { 3oz. water } \\
\text { swallow }\end{array}$ & 88 & 22 \\
\hline Standardized swallowing assessment & VFSS & Yes & No & $\begin{array}{l}\text { 1. } 5 \mathrm{ml} \times 3 \\
\text { 2. Cup drinking }\end{array}$ & 68 & 86 \\
\hline Timed tests of hinds and wiles & Symptom quest. & Yes & No & $\begin{array}{l}\text { 1. } 5-10 \mathrm{ml} \\
\text { 2. } 100-150 \mathrm{ml}\end{array}$ & 73 & 67 \\
\hline Bedside swallow assessment & VFSS/CE & Yes & No & $\begin{array}{l}\text { 1. } 5 \mathrm{ml} \times 3 \\
\text { 2. } 60 \mathrm{ml}\end{array}$ & 70 & 66 \\
\hline $\begin{array}{l}\text { Toronto bedside swallowing screening } \\
\text { test }\left(\mathrm{TOR}-\mathrm{BSST}^{\odot} \text { ) }\right.\end{array}$ & VFSS & Yes & Yes & $\begin{array}{l}\text { 1. } 5 \mathrm{ml} \\
\text { swallow } \times 10 \\
\text { 2. Cup sip }\end{array}$ & 91.3 & 66.7 \\
\hline Clinical examination & VFSS & Yes & No & N/A & 92 & 67 \\
\hline $\begin{array}{l}\text { Modified mann assessment of } \\
\text { swallowing ability (MMASA) }\end{array}$ & MASA & Yes & No & N/A & 93 & 86 \\
\hline
\end{tabular}

sensitivity and specificity (Table 2). Several of these tests are used not only for screening, but also for bedside assessments. Most tools assess a few clinical features and/ or a water swallowing trial. Daniels et al. [48] proposed a screen that does not include a water swallowing trial, but has comparable sensitivity and specificity to other tests involving water swallowing trials. The screening is considered positive if any two of the following are present: (1) dysphonia, (2) dysarthria, (3) abnormal gag, (4) abnormal volitional cough, (5) cough after swallowing, or (6) voice changes after swallow. The Toronto bedside swallowing screening test $\left(\mathrm{TOR}_{-} \mathrm{BSST}^{\odot}\right.$ ) is the only screening tool to includes an assessment of pharyngeal sensation [49].

In a systematic review of bedside screening tests, Bours et al. proposed a water swallowing test combined with pulse oximetry with end points of coughing, dysphonia, and choking as a method to screen patients with dysphagia and aspiration [50, 51].

In attempt to validate a physician-specific tool for screening dysphagia, Antonios et al. [52] have proposed the use of The modified Mann assessment of swallowing ability (MMASA). Their preliminary findings suggest that the MMASA is valid and reliable for screening stroke survivors with dysphagia.

\section{Diagnostic evaluation of dysphagia: bedside and instrumental assessment}

Many bedside and instrumental tools have been developed for the diagnosis and treatment of post-stroke dysphagia. These tools acquire data with regard to pressure, range, strength of structural movement, airway protection, sensation, bolus clearance and efficiency, and bolus flow patterns [53].

Dysphagia evaluation tools can be grouped broadly as imaging (ultrasound, videofluroscopy, Fiberoptic endoscopic evaluation of swallowing, and fiber optic endoscopic evaluation of swallowing with sensory testing) and non-imaging (beside assessment tools, and pharyngeal manometry).

\section{Clinical bedside assessments}

Carnaby-Mann and Lenius [54] defined a dysphagia clinical bedside assessment as encompassing clinical history, and thorough examinations of the oral, pharyngeal, and laryngeal anatomy. In addition, a neurological examination focusing on sensory and motor function, cognitive, behavioral, language abilities, and a trial of feeding should be performed if clinical indicated $[54,55]$. Clinical bedside assessments are inexpensive, noninvasive, and easy to perform by speech language pathologists. The initial evaluation provides the foundation on which a treatment plan can be synthesized [56, 57].

Though clinical evaluation provides valuable information, sensitivity and specificity for identifying aspiration risk is generally low [58-60]. Many clinical assessment tools have been proposed for dysphagia [61-64].

Videofluorographic swallowing study (VFSS)

The VFSS, also known as modified barium swallowing (MBS) study, is considered the gold standard for evaluation of oropharyngeal dysphagia $[65,66]$. The VFSS usually is performed by a speech language pathologist and physician 
Table 3 Behavioral treatment approaches

\begin{tabular}{lll}
\hline Compensatory & Both & Rehabilitative \\
\hline Postural adjustments & Effortful swallow & Tongue hold exercise \\
Altering bolus & Mendelsohn maneuver & Shaker exercise (head-raise) \\
Characteristics (consistency, viscosity, & Supraglottic safety swallow and super & Lingual exercise/resistance training \\
volume of bolus, temperature, taste) & supraglottic safety swallow (breath hold) & LSVT \\
& & EMST \\
Increase volitional control & Increase sensory input & NMES \\
\hline
\end{tabular}

LSVT Lee Silverman voice therapy; EMST expiratory muscle strength training; NMES neuromuscular electrical stimulation [114]

(Physiatrist or Radiologist), and allows direct visualization of bolus flow, swallowing physiology, and airway invasion in real time. The ability to observe the oropharyngeal phase of swallowing allows clinicians to characterize the mechanism and severity of impairment. The VFSS also allows the clinician to observe the important relationships between swallowing, food consistency, position, and ventilation [53, 66]. The protocol described by Logemann et al. [67] in 1993 continues to be followed in most clinical settings. The process involves anteroposterior and lateral view of the oral-pharyngeal phase, with slow motion features to allow characterization of the swallow mechanism and severity of dysfunction. Lateral view allows assessment of oral-pharyngeal transit time, delay, and physiological problems. Anterior views delineate residue asymmetries in the valleculae and pyriform sinuses, and visualize adduction/ abduction of the vocal folds. Specifically the study measures the speed and efficiency of swallow, and defines the movement patterns of the oral cavity, pharynx and larynx. By knowing where, when, and how much aspiration occurs during the study the clinician can evaluate effectiveness of planed rehabilitation strategies.

Most recently, a protocol has been developed for standardization of the VFSS [66]. The development of the Modified Barium Swallow Impairment Profile (MBSImp) allows quantification of swallowing impairments identified during VFSS.

Fiberoptic endoscopic evaluation of swallowing (FEES)

Fiberoptic endoscopic evaluation of swallowing (FEES) often complements the VFSS where limitations exist [6871]. FEES is a safe and well tolerated procedure done by both the otolaryngologist and/or speech pathologist alone $[72,73]$. FEES is as or more sensitive than VFSS in assessing delayed swallow initiation, pharyngeal residue, and aspiration [74-76]. The FEES examination uses flexible endoscopy for evaluation of static and dynamic pharyngeal anatomy, the presence and ability to manage oropharyngeal secretions, and swallowing different consistencies of solids and liquids [77]. During swallowing, transition duration, evidence of penetration and aspiration, the number of swallows to clear the bolus, and the extent of airway closure is noted. The scope is advanced trans-nasally along the floor of the nose until the end of the scope is at the base of uvula or at the tip of the epiglottis. This allows visualization of tongue base, lateral and posterior pharyngeal walls, pyriform sinus, and endolarynx.

In the mid-1990's Aviv et al. [78] introduced fiberoptic endoscopic evaluation of swallowing with sensory testing (FEESST). FEESST is similar to FEES, but includes controlled air pulses to allow objective determination of laryngopharyngeal sensory discrimination thresholds. The air pulses are increased in pressure until a laryngeal adductor reflex (LAR) is elicited. The normal LAR has been established as less than $4.0 \mathrm{~mm} \mathrm{Hg}$ [79]. Utility of LAR is questioned by some clinicians due to intra-rater and inter-rater reliability [80]. Laryngeal sensation as measured during FEESST is not an important factor when evaluating swallowing of pureed foods. [81] A prospective, randomized comparison of FEESST and VFSS demonstrated similar rates of aspiration pneumonia in both groups [82].

Some proponents of FEES and FEESST feel these tests have surpassed the gold standard of VFSS. However, it is important to note that while sensation and vocal cord pathology are best evaluated with FEES, the oral and esophageal segments are poorly assessed. VFSS remains the best way to visualize these areas. Thus, VFSS and FEES/FEESST have different clinical applications [80].

\section{Pharyngeal manometry}

Pharyngoesophageal manometry is used to investigate physiological functions of the upper esophageal sphincter, integrity of the pharyngeal peristalsis, and intrabolus pressures. Esophageal manometry is the gold standard for evaluation of esophageal motor function. However, it is not the primary diagnostic tool for dysphagia in stroke, and is performed only when history, videoflurography, or endoscopy has failed to provide diagnosis or point to a motor disorder. Manometry usually is performed by a gastroenterologist, and 
is indicated in dysphagia with solid food associated with weight loss and regurgitation. The American Gastroenterological Association has provided a technical review on the indication of manometry in relation to other diagnostic tools for assessment of dysphagia [56, 83].

\section{Treatment of dysphagia post stroke}

Through interview, clinical swallow evaluations, and instrumental assessments, the clinician gathers information regarding the patient's cognition, physiological impairments, sensory impairments, and appropriateness for initiation of oral intake. During objective assessments, the effectiveness of compensatory strategies is evaluated to provide the patient with the safest yet least restrictive diet. The information gathered from these assessments then is used to develop an appropriate and individualized rehabilitation program.

Dysphagia rehabilitation is comprised of both compensatory and rehabilitative approaches [84]. Compensatory strategies are used to reduce symptoms of dysphagia without altering the physiology, while rehabilitative approaches are designed to improve swallowing physiology and improve swallow safety and tolerance of the least restrictive diet [85].

Some strategies are both compensatory and rehabilitative in nature, in that they may eliminate symptoms of dysphagia acutely, and when used over time, improve swallowing physiology (Table 3). Several techniques are commonly applied in dysphagia rehabilitation. Traditional treatment techniques include tongue strengthening exercises, thermal-tactile stimulation, tongue hold exercises, Mendelsohn maneuver, supraglottic and super-supraglottic swallow, effortful swallow, and the Shaker exercise [86].

After an objective assessment, compensatory strategies and a combination of traditional therapy techniques are initiated. Traditional therapy techniques significantly improve swallowing physiology with each exercise having a different impact on the swallow [87•].

However, it can be difficult to attribute the improvement to any one technique, as they are often used in combination [88•]. Table 4 describes traditional therapies and their expected effects in more detail.

Biofeedback methods, such as surface electromyography (sEMG) have been used in conjunction with traditional therapy approaches to "increase awareness of swallowing patterns and to help the patient modify, monitor, and challenge performance while executing swallowing maneuvers" [89]. sEMG has been reported to increase the rate of progress seen in traditional therapy approaches for patients with chronic dysphagia [90]. In a retrospective study of stroke survivors or head and neck cancer patients, the use of biofeedback with traditional therapy approaches significantly improved swallowing function and oral diet tolerance, with the stroke survivors benefitting more than the cancer patients [90].

Neuromuscular electrical stimulation (NMES) has gained increased attention due to the controversy surrounding its effectiveness as a treatment approach for dysphagia. NMES has been used to retrain pharyngeal musculature, improve swallow function, and promote reorganization of the motor cortex [91]. Permsirivanich et al. (2009) conducted a randomized controlled trial comparing NMES to traditional therapy techniques. Both treatment approaches were found to positively impact swallow function, with NMES having slightly better outcomes [92]. Conversely, in Bulow's et al. [91] randomized study comparing NMES and traditional treatment, all subjects had significant improvements in swallow function, but the differences between the two treatment groups was not significant. A study by Ludlow et al. [93] found that the surface electrical stimulation used was either too weak or did not penetrate the mucosa deep enough to stimulate the muscles responsible for hyolaryngeal elevation. Their findings suggest electrical stimulation could be used for

Table 4 Dysphagia therapeutic techniques

\begin{tabular}{lc}
\hline Treatment technique & Effect on swallow function \\
\hline Effortful swallow & $\begin{array}{c}\text { Improves base of tongue retraction during the swallow and improves } \\
\text { clearance of the bolus from the vallecula } \\
\text { Increases extent and duration of laryngeal elevation and thereby } \\
\text { enhancing during and width of cricopharyngeal opening }\end{array}$ \\
Shaker exercise (head lift exercise) & $\begin{array}{c}\text { Indicated for patients with reduced extent or duration of } \\
\text { cricopharyngeal opening resulting in pyriform sinus residue }\end{array}$ \\
Supraglottic safety swallow & $\begin{array}{c}\text { Breath hold closes vocal folds prior to swallow initiation and clears } \\
\text { possible residue from the laryngeal vestibule } \\
\text { Increase chance of true vocal fold and false vocal fold closure by } \\
\text { bearing down }\end{array}$ \\
Tongue hold exercise & $\begin{array}{c}\text { Improves contact between the base of tongue and posterior pharyngeal } \\
\text { wall }\end{array}$ \\
\hline
\end{tabular}


patients with weakened musculature who are able to elevate the larynx during the swallow. However, for patients who were unable to elevate the larynx during the swallow, electrical stimulation was found to negatively impact laryngeal elevation, resulting in increased difficulty for airway protection and increased risk of aspiration. Leelamanit et al. [94] found that surface electrical stimulation resulted in improved laryngeal elevation that may positively affect cricopharyngeal opening. Given the inconsistencies in the literature, it is unclear whether neuromuscular electrical stimulation for the treatment of dysphagia is effective.

For stroke survivors, a reduction in lingual strength may have serious implications on swallowing function. According to Hewitt and colleagues (2008), decreased lingual muscle mass can negatively impact bolus propulsion into the pharynx [95]. As there is an increased emphasis on the diagnosis and treatment of lingual dysfunction, several devices are being used to evaluate tongue force and pressure output. These include the iowa oral performance instrument (IOPI), tongue force measurement system (TOMS), Kay Elemetrics swallowing workstation lingual force transducer, and the Madison oral strengthening therapeutic device (MOST). A prospective cohort intervention study in acute stroke survivors, found that an isometric lingual exercise program utilizing the IOPI was effective in increasing isometric pressures for the anterior and posterior tongue, increasing maximum swallowing pressures, significantly decreasing overall residue, and improving penetration-aspiration ratings [96].

Although positive results have been found in the use of sEMG, NMES, and isometric lingual exercise programs, continued research is needed to determine their effectiveness in stroke survivors. However, the positive results found in sEMG and isometric lingual exercise programs are promising. These interventions are likely to play a role in dysphagia therapy in combination with traditional therapy approaches for the rehabilitation of dysphagia.

Disclosure M González-Fernández, L Ottenstein, L Atanelov, and $\mathrm{AB}$ Christian declares no conflicts of interest.

\section{References}

Papers of particular interest, published recently, have been highlighted as:

- Of importance

1. Centers for Disease Control and Prevention. FastStats: cerebrovascular disease or stroke. http://www.cdc.gov/nchs/fastats/ stroke.htm (2013). Accessed 23 Jan 2013.

2. Martino R, Foley N, Bhogal S, Diamant N, Speechley M, Teasell R. Dysphagia after stroke: incidence, diagnosis, and pulmonary complications. Stroke. 2005;36(12):2756-63.
3. Smithard DG, O'Neill PA, England RE, et al. The natural history of dysphagia following a stroke. Dysphagia. 1997;12(4): 188-93.

4. Mann G, Hankey GJ, Cameron D. Swallowing function after stroke: prognosis and prognostic factors at 6 months. Stroke. 1999;30(4):744-8.

5. Broadley S, Croser D, Cottrell J, et al. Predictors of prolonged dysphagia following acute stroke. J Clin Neurosci. 2003;10(3): 300-5.

6. Smithard DG, O'Neill PA, Parks C, Morris J. Complications and outcome after acute stroke. Does dysphagia matter? Stroke. 1996;27(7):1200-4.

7. Finestone HM, Greene-Finestone LS, Wilson ES, Teasell RW. Malnutrition in stroke patients on the rehabilitation service and at follow-up: prevalence and predictors. Arch Phys Med Rehabil. 1995;76(4):310-6.

8. Gordon C, Hewer RL, Wade DT. Dysphagia in acute stroke. Br Med J (Clin Res Ed). 1987;295(6595):411-4.

9. Ekberg O, Hamdy S, Woisard V, Wuttge-Hannig A, Ortega P. Social and psychological burden of dysphagia: its impact on diagnosis and treatment. Dysphagia. 2002;17(2):139-46. doi: 10.1007/s00455-001-0113-5.

10. Logemann JA. Evaluation and treatment of swallowing disorders. 2nd ed. Austin: Pro-Ed; 1998.

11. Cecconi E, Di Piero V. Dysphagia-pathophysiology, diagnosis and treatment. Front Neurol Neurosci. 2012;30:86-9. doi: $10.1159 / 000333423$.

12. Miller AJ. The neurobiology of swallowing and dysphagia. Dev Disabil Res Rev. 2008;14(2):77-86. doi:10.1002/ddrr.12.

13. Matsuo K, Palmer JB. Anatomy and physiology of feeding and swallowing: Normal and abnormal. Phys Med Rehabil Clin N Am. 2008;19(4):691-707. doi:10.1016/j.pmr.2008.06.001.

14. Casas MJ, Kenny DJ, Macmillan RE. Buccal and lingual activity during mastication and swallowing in typical adults. J Oral Rehabil. 2003;30(1):9-16.

15. Mioche L, Hiiemae KM, Palmer JB. A postero-anterior videofluorographic study of the intra-oral management of food in man. Arch Oral Biol. 2002;47(4):267-80.

16. Palmer JB, Hiiemae KM, Liu J. Tongue-jaw linkages in human feeding: a preliminary videofluorographic study. Arch Oral Biol. 1997;42(6):429-41.

17. Palmer JB, Rudin NJ, Lara G, Crompton AW. Coordination of mastication and swallowing. Dysphagia. 1992;7(4):187-200.

18. Kendall KA, McKenzie S, Leonard RJ, Goncalves MI, Walker A. Timing of events in normal swallowing: a videofluoroscopic study. Dysphagia. 2000;15(2):74-83.

19. Martin-Harris B, Brodsky MB, Michel Y, Ford CL, Walters B, Heffner J. Breathing and swallowing dynamics across the adult lifespan. Arch Otolaryngol Head Neck Surg. 2005;131(9): 762-70.

20. Perlman AL, Palmer PM, McCulloch TM, Vandaele DJ. Electromyographic activity from human laryngeal, pharyngeal, and submental muscles during swallowing. J Appl Physiol. 1999; 6(5):1663-9.

21. Kahrilas PJ, Logemann JA, Lin S, Ergun GA. Pharyngeal clearance during swallowing: a combined manometric and videofluoroscopic study. Gastroenterology. 1992;103(1):128-36.

22. Palmer JB, Tanaka E, Ensrud E. Motions of the posterior pharyngeal wall in human swallowing: a quantitative videofluorographic study. Arch Phys Med Rehabil. 2000;81(11):1520-6.

23. Cook IJ, Dodds WJ, Dantas RO, et al. Opening mechanisms of the human upper esophageal sphincter. Am J Physiol. 1989;257 (5 Pt 1):G748-59.

24. Palmer JB, Hiiemae KM. Eating and breathing: interactions between respiration and feeding on solid food. Dysphagia. 2003;18(3):169-78. 
25. Ohmae Y, Logemann JA, Kaiser P, Hanson DG, Kahrilas PJ. Timing of glottic closure during normal swallow. Head Neck. 1995;17(5):394-402.

26. Shaker R, Dodds WJ, Dantas RO, Hogan WJ, Arndorfer RC. Coordination of deglutitive glottic closure with oropharyngeal swallowing. Gastroenterology. 1990;98(6):1478-84.

27. Martin BJ, Logemann JA, Shaker R, Dodds WJ. Coordination between respiration and swallowing: respiratory phase relationships and temporal integration. J Appl Physiol. 1994;76(2):714-23.

28. Hiss SG, Treole K, Stuart A. Effects of age, gender, bolus volume, and trial on swallowing apnea duration and swallow/ respiratory phase relationships of normal adults. Dysphagia. 2001;16(2):128-35

29. Shaw DW, Cook IJ, Gabb M, et al. Influence of normal aging on oral-pharyngeal and upper esophageal sphincter function during swallowing. Am J Physiol. 1995;268(3 Pt 1):G389-96.

30. Broussard DL, Altschuler SM. Brainstem viscerotopic organization of afferents and efferents involved in the control of swallowing. Am J Med. 2000;108(Suppl 4a):79S-86S.

31. Jean A. Brain stem control of swallowing: neuronal network and cellular mechanisms. Physiol Rev. 2001;81(2):929-69.

32. Jean A. Brainstem organization of the swallowing network. Brain Behav Evol. 1984;25(2-3):109-16.

33. Miller AJ. Deglutition. Physiol Rev. 1982;62(1):129-84.

34. Aydogdu I, Ertekin C, Tarlaci S, Turman B, Kiylioglu N, Secil Y. Dysphagia in lateral medullary infarction (wallenberg's syndrome): an acute disconnection syndrome in premotor neurons related to swallowing activity? Stroke. 2001;32(9):2081-7.

35. German RZ, Palmer JB. Anatomy and development of oral cavity and pharynx. GI Motil Online. 2006. http://www.nature. com/gimo/contents/pt1/full/gimo5.html. Accessed 23 Jan 2013.

36. Shaker R, Ren J, Podvrsan B, et al. Effect of aging and bolus variables on pharyngeal and upper esophageal sphincter motor function. Am J Physiol. 1993;264(3 Pt 1):G427-32.

37. Lang IM. Brain stem control of the phases of swallowing. Dysphagia. 2009;24(3):333-48. doi:10.1007/s00455-009-92116.

38. Kim H, Chung CS, Lee KH, Robbins J. Aspiration subsequent to a pure medullary infarction: lesion sites, clinical variables, and outcome. Arch Neurol. 2000;57(4):478-83.

39. Hamdy S, Aziz Q, Rothwell JC, et al. Explaining oropharyngeal dysphagia after unilateral hemispheric stroke. Lancet. 1997;350(9079):686-92.

40. - Leopold NA, Daniels SK. Supranuclear control of swallowing. Dysphagia. 2010;25(3):250-257. doi: 10.1007/s00455-0099249-5. Summarizes the supranuclear control of swallowing.

41. Michou E, Hamdy S. Cortical input in control of swallowing. Curr Opin Otolaryngol Head Neck Surg. 2009;17(3):166-71. doi:10.1097/MOO.0b013e32832b255e.

42. Hamdy S, Aziz Q, Rothwell JC, et al. Recovery of swallowing after dysphagic stroke relates to functional reorganization in the intact motor cortex. Gastroenterology. 1998;115(5):1104-12.

43. Hamdy S, Aziz Q, Rothwell JC, et al. The cortical topography of human swallowing musculature in health and disease. Nat Med. 1996;2(11):1217-24.

44. Hamdy S. The organisation and re-organisation of human swallowing motor cortex. Suppl Clin Neurophysiol. 2003;56: 204-10.

45. Ertekin C, Aydogdu I, Tarlaci S, Turman AB, Kiylioglu N. Mechanisms of dysphagia in suprabulbar palsy with lacunar infarct. Stroke. 2000;31(6):1370-6.

46. Cola MG, Daniels SK, Corey DM, Lemen LC, Romero M, Foundas AL. Relevance of subcortical stroke in dysphagia. Stroke. 2010;41(3):482-6. doi:10.1161/STROKEAHA.09. 66133.
47. Hamdy S, Rothwell JC, Brooks DJ, Bailey D, Aziz Q, Thompson DG. Identification of the cerebral loci processing human swallowing with H2(15)O PET activation. J Neurophysiol. 1999;81(4):1917-26.

48. Daniels SK, McAdam CP, Brailey K, Foundas AL. Clinical assessment of swallowing and prediction of dysphagia severity. Am J Speech Lang Pathol. 1997;6:17-24.

49. Martino R, Silver F, Teasell R, et al. The toronto bedside swallowing screening test (TOR-BSST): development and validation of a dysphagia screening tool for patients with stroke. Stroke. 2009;40(2):555-61. doi:10.1161/STROKEAHA.107.510370.

50. Bours GJ, Speyer R, Lemmens J, Limburg M, de Wit R. Bedside screening tests vs. videofluoroscopy or fibreoptic endoscopic evaluation of swallowing to detect dysphagia in patients with neurological disorders: Systematic review. J Adv Nurs. 2009;65(3):477-93. doi:10.1111/j.1365-2648.2008.04915.x.

51. Nishimiya J, Yamaji Y, Nitta T, et al. A 49-year-old man with progressive dysarthria, dysphagia, and left hemiparesis. No To Shinkei. 1995;47(11):1109-18.

52. Antonios N, Carnaby-Mann G, Crary M, et al. Analysis of a physician tool for evaluating dysphagia on an inpatient stroke unit: the modified mann assessment of swallowing ability. J Stroke Cerebrovasc Dis. 2010;19(1):49-57. doi:10.1016/j.jstrokecerebrovasdis.2009.03.007.

53. Martin-Harris B, Jones B. The videofluorographic swallowing study. Phys Med Rehabil Clin N Am. 2008;19(4):769-85. doi: 10.1016/j.pmr.2008.06.004.

54. Carnaby-Mann G, Lenius K. The bedside examination in. Dysphagia. 2008;19:747-68.

55. Ricci Maccarini A, Filippini A, Padovani D, Limarzi M, Loffredo M, Casolino D. Clinical non-instrumental evaluation of dysphagia. Acta Otorhinolaryngol Ital. 2007;27(6):299-305.

56. Cook IJ. Diagnostic evaluation of dysphagia. Nat Clin Pract Gastroenterol Hepatol. 2008;5(7):393-403. doi:10.1038/ncpgasthep1153.

57. Mann G, Hankey GJ, Cameron D. Swallowing disorders following acute stroke: prevalence and diagnostic accuracy. Cerebrovasc Dis. 2000;10(5):380-6. doi:16094.

58. Daniels SK, Brailey K, Priestly DH, Herrington LR, Weisberg LA, Foundas AL. Aspiration in patients with acute stroke. Arch Phys Med Rehabil. 1998;79(1):14-9.

59. Langmore SE, Terpenning MS, Schork A, et al. Predictors of aspiration pneumonia: how important is dysphagia? Dysphagia. 1998;13(2):69-81.

60. Gonzalez-Fernandez M, Sein MT, Palmer JB. Clinical experience using the mann assessment of swallowing ability for identification of patients at risk for aspiration in a mixed-disease population. Am J Speech Lang Pathol. 2011;20(4):331-6. doi: 10.1044/1058-0360(2011/10-0082).

61. Trapl M, Enderle P, Nowotny M, et al. Dysphagia bedside screening for acute-stroke patients: the gugging swallowing screen. Stroke. 2007;38(11):2948-52. doi:10.1161/STROKEAHA.107.483933.

62. Splaingard ML, Hutchins B, Sulton LD, Chaudhuri G. Aspiration in rehabilitation patients: videofluoroscopy vs bedside clinical assessment. Arch Phys Med Rehabil. 1988;69(8): 637-40.

63. DePippo KL, Holas MA, Reding MJ. Validation of the 3-oz water swallow test for aspiration following stroke. Arch Neurol. 1992;49(12):1259-61.

64. Tohara H, Saitoh E, Mays KA, Kuhlemeier K, Palmer JB. Three tests for predicting aspiration without videofluorography. Dysphagia. 2003;18(2):126-34.

65. Palmer JB, Kuhlemeier KV, Tippett DC, Lynch C. A protocol for the videofluorographic swallowing study. Dysphagia. 1993;8(3):209-14. 
66. Martin-Harris B, Brodsky MB, Michel Y, et al. MBS measurement tool for swallow impairment-MBSImp: establishing a standard. Dysphagia. 2008;23:392-405.

67. Logemann JA. Manual for the videofluorographic study of swallowing. 2nd ed. Austin: Pro-Ed Inc; 1993.

68. Warnecke T, Ritter MA, Kröger B, et al. Fiberoptic endoscopic dysphagia severity scale predicts outcome after acute stroke. Cerebrovasc Dis. 2009;28(3):283-9.

69. Hafner G, Neuhuber A, Hirtenfelder S, Schmedler B, Eckel HE. Fiberoptic endoscopic evaluation of swallowing in intensive care unit patients. Eur Arch Otorhinolaryngol. 2008;265(4):441-6.

70. Doggett DL, Turkelson CM, Coates V. Recent developments in diagnosis and intervention for aspiration and dysphagia in stroke and other neuromuscular disorders. Curr Atheroscler Rep. 2002;4(4):304-11.

71. Rao N, Brady S, Chaudhuri G, Donzelli J, Wesling M. Goldstandard? Analysis of the videofluoroscopic and fiberoptic endoscopic swallow examinations. J Appl Res. 2003;3:89-96.

72. Willging JP, Thompson DM. Pediatric FEESST: fiberoptic endoscopic evaluation of swallowing with sensory testing. Curr Gastroenterol Rep. 2005;7(3):240-3.

73. Cohen MA, Setzen M, Perlman PW, Ditkoff M, Mattucci KF, Guss J. The safety of flexible endoscopic evaluation of swallowing with sensory testing in an outpatient otolaryngology setting. Laryngoscope. 2003;113(1):21-4. doi:10.1097/0000553 7-200301000-00004.

74. Leder SB, Sasaki CT, Burrell MI. Fiberoptic endoscopic evaluation of dysphagia to identify silent aspiration. Dysphagia. 1998;13(1):19-21.

75. Langmore SE, Schatz K, Olson N. Endoscopic and videofluoroscopic evaluations of swallowing and aspiration. Ann Otol Rhinol Laryngol. 1991;100(8):678-81.

76. Langmore SE. Evaluation of oropharyngeal dysphagia: which diagnostic tool is superior? Curr Opin Otolaryngol Head Neck Surg. 2003;11:485-9.

77. Leder SB, Murray JT. Fiberoptic endoscopic evaluation of swallowing. Phys Med Rehabil Clin N Am. 2008;19(4): 787-801. doi:10.1016/j.pmr.2008.05.003.

78. Aviv JE, Kim T, Thomson JE, Sunshine S, Kaplan S, Close LG. Fiberoptic endoscopic evaluation of swallowing with sensory testing (FEESST) in healthy controls. Dysphagia. 1998;13(2): $87-92$.

79. Aviv JE, Kim T, Sacco RL, et al. FEESST: a new bedside endoscopic test of the motor and sensory components of swallowing. Ann Otol Rhinol Laryngol. 1998;107(5 Pt 1):378-87.

80. Rees CJ. Flexible endoscopic evaluation of swallowing with sensory testing. Curr Opin Otolaryngol Head Neck Surg. 2006;14(6):425-30. doi:10.1097/MOO.0b013e328010ba88.

81. Perlman PW, Cohen MA, Setzen M, et al. The risk of aspiration of pureed food as determined by flexible endoscopic evaluation of swallowing with sensory testing. Otolaryngol Head Neck Surg. 2004;130(1):80-3. doi:10.1016/j.otohns.2003.09.026.

82. Aviv JE. Prospective, randomized outcome study of endoscopy versus modified barium swallow in patients with dysphagia. Laryngoscope. 2000;110(4):563-74. doi:10.1097/00005537200004000-00008.

83. Pandolfino JE, Kahrilas PJ. AGA technical review on the clinical use of esophageal manometry. Gastroenterology. 2005; 128(1):209-24.

84. Huckabee M, Pelletier C. Management of adult neurogenic dysphagia. 1st ed. San Diego: Singular Publishing Group; 1999.

85. Carnaby-Mann G, Lenius K, Crary M. Update on assessment and management of dysphagia post stroke. Northeast Fla Med. 2007;58(2):31-4.

86. Kiger M, Brown CS, Watkins L. Dysphagia management: an analysis of patient outcomes using VitalStim therapy compared to traditional swallow therapy. Dysphagia. 2006;21(4):243-53. doi:10.1007/s00455-006-9056-1.

87. • van der Kruis JG, Baijens LW, Speyer R, Zwijnenberg I. Biomechanical analysis of hyoid bone displacement in videofluoroscopy: a systematic review of intervention effects. Dysphagia. 2011;26(2):171-182. doi: 10.1007/s00455-010-9318-9. Systematic review of swallowing interventions and their effect on physiologic swallowing parameters.

88. - Speyer R, Baijens L, Heijnen M, Zwijnenberg I. Effects of therapy in oropharyngeal dysphagia by speech and language therapists: a systematic review. Dysphagia. 2010;25(1):40-65. doi: 10.1007/s00455-009-9239-7. Summarizes the literature as it pertains to the effects of dysphagia therapy.

89. Burkhead LM, Sapienza CM, Rosenbek JC. Strength-training exercise in dysphagia rehabilitation: principles, procedures, and directions for future research. Dysphagia. 2007;22(3):251-65. doi:10.1007/s00455-006-9074-z.

90. Crary MA, Carnaby Mann GD, Groher ME, Helseth E. Functional benefits of dysphagia therapy using adjunctive sEMG biofeedback. Dysphagia. 2004;19(3):160-4. doi:10.1007/s004 55-004-0003-8.

91. Bulow M, Speyer R, Baijens L, Woisard V, Ekberg O. Neuromuscular electrical stimulation (NMES) in stroke patients with oral and pharyngeal dysfunction. Dysphagia. 2008;23(3):302-9. doi:10.1007/s00455-007-9145-9.

92. Permsirivanich W, Tipchatyotin S, Wongchai M, et al. Comparing the effects of rehabilitation swallowing therapy vs. neuromuscular electrical stimulation therapy among stroke patients with persistent pharyngeal dysphagia: a randomized controlled study. J Med Assoc Thail. 2009;92(2):259-65.

93. Ludlow CL, Humbert I, Saxon K, Poletto C, Sonies B, Crujido L. Effects of surface electrical stimulation both at rest and during swallowing in chronic pharyngeal dysphagia. Dysphagia. 2006;. doi:10.1007/s00455-006-9029-4.

94. Leelamanit V, Limsakul C, Geater A. Synchronized electrical stimulation in treating pharyngeal dysphagia. Laryngoscope. 2002;112(12):2204-10.

95. Hewitt A, Hind J, Kays S, et al. Standardized instrument for lingual pressure measurement. Dysphagia. 2008;23(1):16-25. doi:10.1007/s00455-007-9089-0.

96. Robbins J, Kays SA, Gangnon RE, et al. The effects of lingual exercise in stroke patients with dysphagia. Arch Phys Med Rehabil. 2007;88(2):150-8. doi:10.1016/j.apmr.2006.11.002.

97. Hamdy S, Mikulis DJ, Crawley A, et al. Cortical activation during human volitional swallowing: an event-related fMRI study. Am J Physiol 1999a;277:G219-25.

98. Hamdy S, Rothwell JC, Brooks DJ, et al. Identification of the cerebral loci processing human swallowing with H2(15)O PET activation. J Neurophysiol 1999b;81:1917-1926.

99. Mosier K, Bereznaya I. Parallel cortical networks for volitional control of swallowing in humans. Exp Brain Res 2001;140:280-289.

100. Martin RE, Goodyear BG, Gati JS, et al. Cerebral cortical representation of automatic and volitional swallowing in humans. J Neurophysiol 2001;85:938-950.

101. Martin RE, MacIntosh BJ, Smith RC, et al. Cerebral areas processing swallowing and tongue movement are overlapping but distinct: a functional magnetic resonance imaging study. J Neurophysiol 2004;92:2428-2443.

102. Mosier KM, Liu WC, Maldjian JA, et al. Lateralization of cortical function in swallowing: a functional MR imaging study. AJNR Am J Neuroradiol 1999b;20:1520-1526.

103. Kern M, Birn R, Jaradeh S, et al. Swallow-related cerebral cortical activity maps are not specific to deglutition. Am J Physiol Gastrointest Liver Physiol 2001;280:G531-8.

104. Toogood JA, Barr AM, Stevens TK, Gati JS, Menon RS, Martin RE. Discrete functional contributions of cerebral cortical foci in 
voluntary swallowing: a functional magnetic resonance imaging (fMRI) "Go, No-Go" study. Exp Brain Res 2005;161:81-90.

105. Daniels SK, Corey DM, Fraychinaud A, et al. Swallowing lateralization: the effects of modified dual-task interference. Dysphagia 2006;21:21-27.

106. Daniels SK, Foundas AL. The role of the insular cortex in dysphagia. Dysphagia 1997;12:146-156.

107. Mosier K, Patel R, Liu WC, et al. Cortical representation of swallowing in normal adults: functional implications. Laryngoscope 1999a; 109:1417-1423.

108. Suzuki M, Asada Y, Ito J, Hayashi K, Inoue H, Kitano H. Activation of cerebellum and basal ganglia on volitional swallowing detected by functional magnetic resonance imaging. Dysphagia 2003;18:71-77.
109. Miller AJ. Deglutition. Physiol Rev 1982;62:129-184.

110. Jean A. Localization and activity of medullary swallowing neurones. J Physiol (Paris) 1972;64:227-268.

111. Jean A. Brainstem organization of the swallowing network. Brain Behav Evol 1984;25:109-116.

112. Jean A. Brain stem control of swallowing: neuronal network and cellular mechanisms. Physiol Rev 2001;81:929-969.

113. Zald DH, Pardo JV. The functional neuroanatomy of voluntary swallowing. Ann Neurol 1999;46:281-286.

114. González-Fernández M, Daniels SK. Dysphagia in stroke and neurologic disease. Phys Med Rehabil Clin N Am 2008;19(4): 867-888. 